\title{
Research on the Social Value of Urban Park Ecosystem Services Based on Population Characteristics Difference
}

\author{
Qian Ma' ${ }^{1}$ Zhanglei Chen ${ }^{2}$, Mingying Zeng1* \\ ${ }^{1}$ Southwest University of Science and Technology, Mianyang, China \\ ${ }^{2}$ School of Architecture and Urban Planning, Chongqing University, Chongqing, China \\ Email: QianMa12@163.com,20181501001@cqu.edu.cn, *zmy018@hotmail.com
}

How to cite this paper: Ma, Q., Chen, Z. L., \& Zeng, M. Y. (2021). Research on the Social Value of Urban Park Ecosystem Services Based on Population Characteristics Difference. Open Journal of Social Sciences, 9, 243-258.

https://doi.org/10.4236/jss.2021.912016

Received: November 12, 2021

Accepted: December 11, 2021

Published: December 14, 2021

Copyright $\odot 2021$ by author(s) and Scientific Research Publishing Inc. This work is licensed under the Creative Commons Attribution International License (CC BY 4.0).

http://creativecommons.org/licenses/by/4.0/

\section{(c) (i) Open Access}

\begin{abstract}
With the development of urbanization, it is very important to know the public perception of urban ecosystem service value with different population characteristics, and it is also one of the prerequisites for strengthening urban management. Based on SolVES model and social preference survey data, this paper evaluates the social value of ecosystem services of Mianyang People's Park. The results show that: 1) The public has a strong perception of park's aesthetic value, historical and cultural value, recreational value, and therapeutic value, and has a high degree of recognition. 2) The gender of the interviewee has an influence on the evaluation of social value. In addition to recreational value, males have more areas with high VI than women, and there are also differences in high VI of the same value. 3) Differences in identities have a greater impact on the spatial distribution of social values. Experts can better consider the supervision and coordination of the construction of ecological culture, while the park staff and tourists tend to provide services such as aesthetics and recreation that can intuitively generate value and benefit. Finally, SolVES model is suitable for perception mapping and value evaluation of comprehensive parks, and the research results can provide basis for park management and optimization.
\end{abstract}

\section{Keywords}

Urban Park, Social Value of Ecosystem Services, Public Perception, Demographic Characteristics, SolVES 


\section{Introduction}

The rapid growth of urban population has intensified the expansion and development of construction land and materials (Spyra et al., 2019). People's pursuit of urban diversification and sustainable development has made the integration and development of urban green space and urban functions an important means of urban planning (Zhang, 2016; Wu et al., 2018; Zeng \& Wu, 2019). We should pay more attention to urban ecosystem services, change the construction mode of urban parks, and match the ecological development goals of cities in the 21st century, so that it has become the focus of urban development to improve the ecological function and social value of green space system (Wu, 2000; Wang, 2017).

In addition, with the gradual deterioration and prominence of ecological environment problems, people pay more and more attention to the maintenance and improvement of urban ecological environment quality (Ni \& Zuo, 2005; Wang \& Ouyang, 2012; Yang \& Zhang, 2016); the influencing factors of human perception and public physical and mental health have been paid attention by scholars (Madureira et al., 2015; Wang et al., 2017). Starting from the demographic characteristics, the influencing factors and using behaviors of urban ecological space perception were studied (Shan \& Xi-Zhang, 2014), and the perceived benefits of ecological space were expanded (Ulrich, 1984; Coon et al., 2011). Moreover, the park green space is used by the public, and the subjectivity and variability of social value perception vary from person to person according to the regional terrain conditions, landscape features, facilities combination and other factors (Graça et al., 2018). Understanding the similarities and differences of public preferences for ecosystem services and social values to identify potential ecological landscape conflicts can provide useful information for greening landscape planning (Castro et al., 2016; McNally et al., 2016; Enriquez-Acevedo et al., 2018).

Everyone is an individual with independent thoughts. Undoubtedly, different population characteristics will have different values. Strumse also pointed out that the gender difference of the public will produce different values in the process of turning to value relationship, and later other scholars' research also confirmed this view (Strumse, 1996; Shuai \& Ping, 2014). In addition, the cultural background (Yu, 1995; Nohl, 2001), education level (Lindemann-Matthies et al., 2010; Molnarova et al., 2012), age (Yamashita, 2002; van den Bosch \& Ode Sang, 2017), professional knowledge (Vouligny, Domon, \& Ruiz, 2009) and familiarity with the environment (Howley, Donoghue, \& Hynes, 2012) will all affect the evaluation. Therefore, the above characteristics of different audiences must be paid attention to in value perception evaluation and landscape design (Zhao, Zhang, \& Wu, 2015). However, most of today's planning and design are directly implemented by experts and planners, and the public's ideas are not fully integrated, which leads to some potential mismatches between actual planning and user perception (Daniels et al., 2018; Graça et al., 2018). Therefore, when planning 
urban parks and other green spaces, we need to know the public's preference, the public's perception of different landscape elements, and reduce the differences between individuals and between experts and the public in treating social values, so as to achieve better evaluation and quantification effects.

Finally, the research on the social value of ecosystem services with parks as the main body has been relatively mature, but most of the achievements are focused on natural ecological parks such as forests and wetlands (Bagstad et al., 2016; Wang et al., 2016; Sun et al., 2019; Tufféry et al., 2021). However, from the perspective of demographic characteristics research, we should focus on the public's preference and perception, and let the public participate as much as possible. Comprehensive parks have the closest relationship with urban residents. As an urban green space that complements urban functions in urban ecosystem, its social value is much higher than that of wetlands and forest parks, which is more conducive to studying the relationship among public perception, social population characteristics and ecosystem services.

Therefore, in this study, aiming at Mianyang People's Comprehensive Park, the SolVES model is used to evaluate and draw the social value of its ecosystem services, to show the types and social values of public landscape preferences and to measure their importance, to reflect the subjective wishes of tourists in planning practice, to fully reflect the needs of the public, to show the coordination and balance of preferences of different stakeholders, to provide some references for the planning, optimization and ecological environment protection of urban comprehensive parks in the future, and to complete the comprehensive park construction model that is closer to the public's wishes and residents' lives to provide more benefits for urban residents.

\section{Methods}

\subsection{Study Area}

Mianyang People's Park is located in the oldest business district in Fucheng District, Mianyang City, Sichuan Province. It was built in 1930 and covers an area of about 15.2 hectares. There are many shopping malls around the park, complete infrastructure, convenient transportation and concentrated traffic. The Park has a profound historical and cultural heritage. As one of Mianyang's patriotic education bases, it has cultural attractions such as Liberation Monument and Deng Jiaxian Square, which carries forward and inherits the historical and cultural heritage and patriotic spirit of "Northwest Sichuan No. 1 Park". In addition, it is also a concentrated garden greening area in the city center. There are more than 100 species of plants in Laurel Garden, Cycad Garden, Peach Blossom Island and other areas, and there are more than 20 ancient and famous trees listed for protection by the government, which has gradually formed a biodiversity protection site within the city. Finally, its Amusement Park, Artificial Lake and other scenic spots are rich in recreational activities and green landscapes, which together enhance the connotation and taste of the park, and make it develop into a com- 
prehensive park integrating nature, history and cultural landscape in the center of the city, integrating culture, education, tourism, fitness, entertainment and leisure (Figure 1).

\subsection{SolVES Model}

Social value for ecosystem services (SolVES) is developed based on the values, attitudes and preferences of different stakeholders, and consists of three modules: social values of ecosystem services, value mapping and value transformation mapping (Sherrouse, Clement, \& Semmens, 2011). The social value survey data of public attitudes and preferences are obtained mainly through questionnaires and interviews, and then spatial data such as environmental layers and study area boundaries are collected. Then, the average nearest neighbor tool in ArcGIS software is embedded into the model, and the model is used to analyze the social value of ecosystem services in the study area. The spatial distribution pattern of each social value type is judged by the feedback average nearest neighbor ratio $(\mathrm{R})$ and its standard deviation $(\mathrm{Z})$. The non-monetized value index

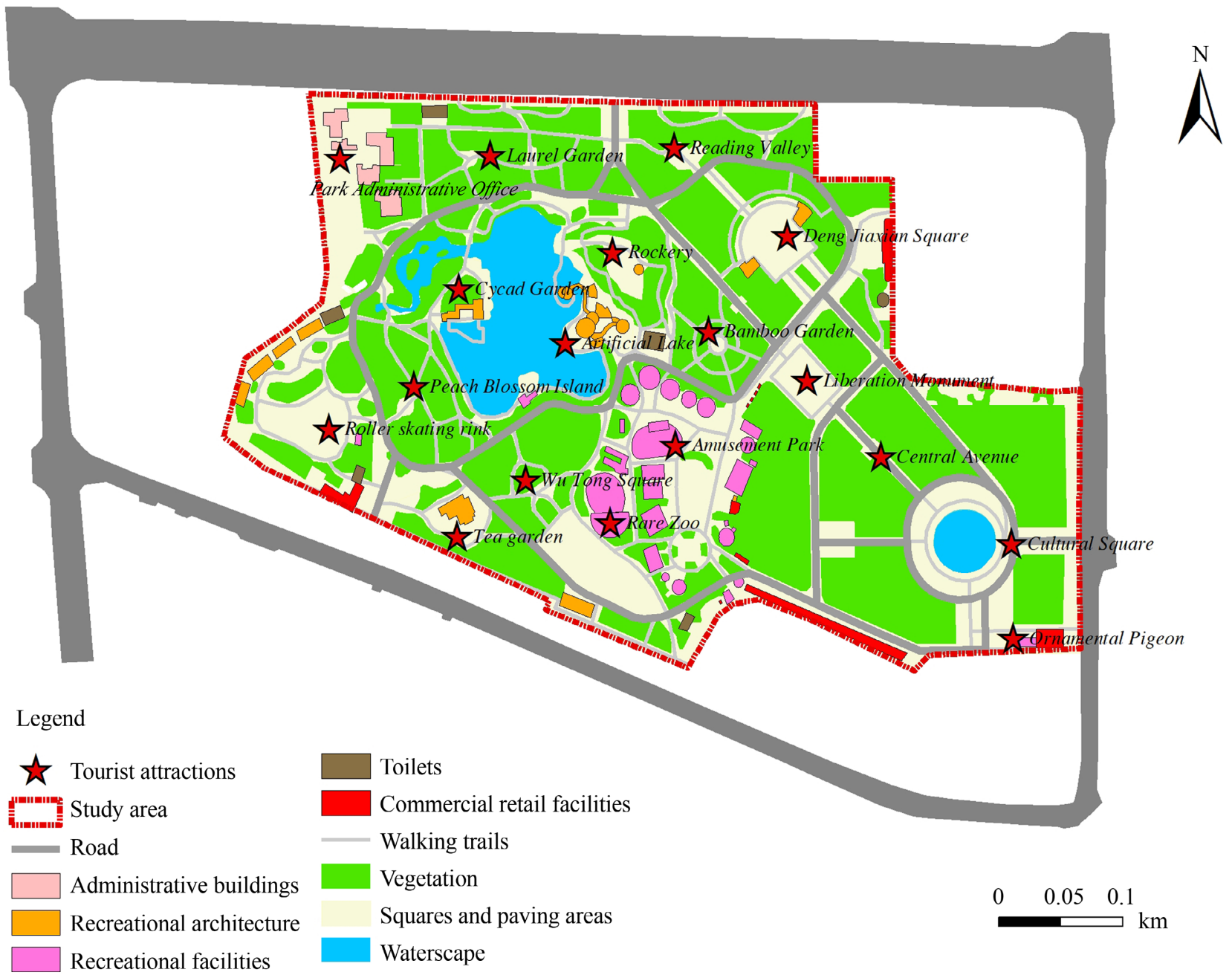

Figure 1. Study the regional plan and main scenic spots. 
(1 - 10) shows the specific spatial position and takes the environmental factors into consideration in value evaluation, which is convenient for analyzing the relationship between social value index and natural environment. This paper attempts to use the social value model and value mapping model of SolVES model to evaluate the social value of ecosystem services of Mianyang People's Park.

\subsection{Data Sources}

\subsubsection{Survey Data}

This study takes Sherrouse and others' evaluation cases of social value of ecosystem services as reference (Clement \& Cheng, 2011), and through pre-investigation such as field visits and unstructured interviews with tourists, the proposed social value types are screened and 9 types are identified. Research the types of social values with strong regional relevance (Table 1). The SolVES model mainly uses questionnaires to obtain the attitudes and preferences of stakeholders on services. This questionnaire is based on the data requirements of USE_TYPE, USE_ATTITUDE, VALUE_ALLOCATION and other data required by the model, based on the research of Y. Wang, Y. Gao, Sherrouse and other domestic and foreign scholars. The experience and questionnaire content are for reference, and the design is based on the actual environmental factors of the study area and the usage of tourists (Sherrouse, Semmens, \& Clement, 2014; Wang et al., 2016; Gao et al., 2017). The questionnaire contains three parts: 1) Understanding of tourists' play characteristics and satisfaction levels; 2) Respondents assigning

Table 1. Descriptions of the 9 types of social values employed in this study (adapted from Clement \& Cheng, 2011).

\begin{tabular}{|c|c|}
\hline Social value type & Description \\
\hline Aesthetic & Places with beautiful scenery. \\
\hline Biodiversity & Places with many kinds of plants and animals. \\
\hline Economic & Places with shops, for-profit facilities. \\
\hline Historical and cultural & Places with cultural atmosphere, historical sites. \\
\hline $\begin{array}{l}\text { Scientific Research } \\
\text { and Educational }\end{array}$ & $\begin{array}{l}\text { Places with educational and } \\
\text { scientific research significance. }\end{array}$ \\
\hline \multirow[t]{2}{*}{ Life Sustaining } & Places that can purify the air and adjust the climate \\
\hline & $\begin{array}{l}\text { A place for walking slowly. } \\
\text { A place for dancing, singing, } \\
\text { and musical instrument sketching. }\end{array}$ \\
\hline \multirow[t]{3}{*}{ Recreation } & Children's play area. \\
\hline & $\begin{array}{l}\text { A place for drinking tea and chatting, } \\
\text { playing cards and chess, and amusing birds. }\end{array}$ \\
\hline & A place for meditation and reading. \\
\hline Spiritual & Places where one can relax and calm down. \\
\hline Therapeutic & Places to exercise and enhance physical fitness. \\
\hline
\end{tabular}


social value and marking social value points; 3 ) Respondent's basic demographic characteristics. The second part and the third part are the main content. In the second part of the value point marking, respondents are required to assign 100 points of assumed points to 9 social values based on their play experience. The categories that obtain the points must be marked out in the garden. The most valuable scenic spots in this category ( 3 - 5 for each type). The third part collects data such as gender, age, and professional knowledge of tourists to study the relationship between demographic characteristics and social value.

Questionnaire is distributed by tourists' self-filling. In the process of value allocation and social value marking, try to avoid explaining options to tourists in detail to ensure the objectivity of data. On November 14th and 15th, 2020, a preliminary on-the-spot investigation was conducted on the preliminary related issues. During this process, more than 30 tourists were randomly interviewed to learn about the tourists' playing experience and service experience, and the value type was determined and the questionnaire was adjusted according to the tourists' reflection and opinions on the value of the park. Finally, from the beginning of December 2020 to the end of January next year, formal investigation and data collection were conducted, which ensured the accuracy of the data in time. A total of 205 questionnaires were distributed, 205 of which were recovered and 200 of which were valid, with an effective rate of $97.56 \%$. The distribution of questionnaires was based on the number of 150,161,184 questionnaires issued by Peng, Cheng, Zhou and other research institutes, which ensured the rationality of the sample size (Cheng et al., 2018; Peng et al., 2019; Zhou et al., 2020).

\subsubsection{Geospatial Data}

The geospatial data required by the model includes the Shapefile file and raster dataset of the study area. The spatial registration of Mianyang People's Park was carried out by ArcGIS, and the Shapefile file of the study area was obtained by mapping vectorization operation, and the value points marked by respondents were digitized to obtain the social value point layer. The operation of the model should be based on at least one environmental layer, that is, raster dataset. In this study, the distance to water (DTW), which can effectively reflect the spatial relationship of elements, is selected to meet the operation of the model.

\section{Result}

\subsection{Characteristics of Interviewees}

The social demographic chart of the respondents in People's Park is shown in Figure 2. The gender composition of the respondents in People's Park is $46 \%$, slightly lower than that of women. All ages are covered, but $76.5 \%$ of the respondents are under 40 years old, indicating that the respondents are generally younger, which ensures that they have more active thinking and wider attention. In addition, $90.5 \%$ of the respondents have college degree or above (including postgraduate degree or above), which indicates that the respondents are highly 


\section{Gender}

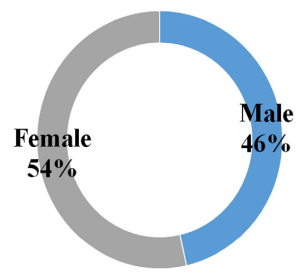

\section{Education Groups}

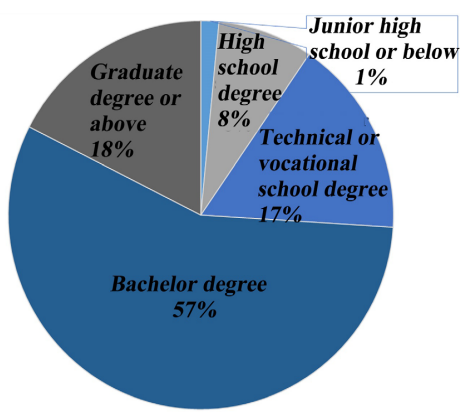

\section{Family Address Groups}

Other areas outside Sichuan, $9.0 \%$

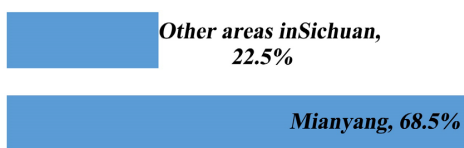

\section{Job Groups}

Other occupations, $9.5 \%$

Retirement, $1.5 \%$

Unemployment. 1.0\%

\section{Income Groups}

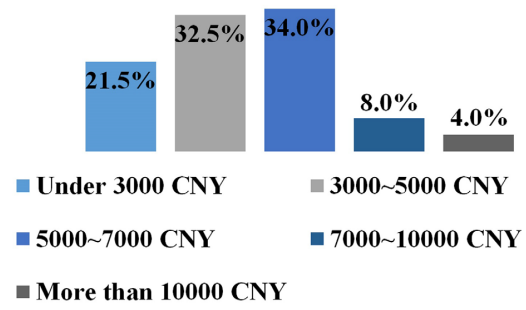

\section{Identity Groups}

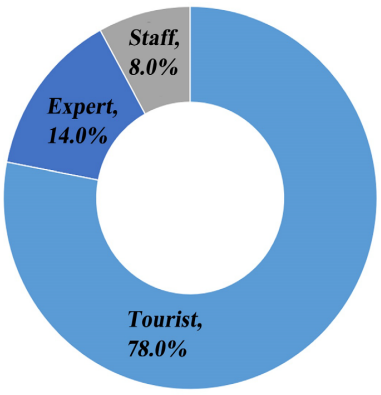

\section{Age Groups}

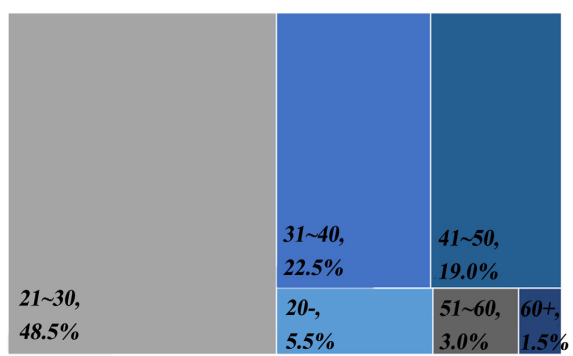

Farmer, 2.5\%

Figure 2. Socio-demographic information of the sample population in percentage (\%).

educated and can well understand the contents of the questionnaire. Finally, most of the respondents have middle incomes of 3000, 5000 (32.5\%) and 5000, 7000 (34\%), and their occupations basically cover all kinds of jobs in the society, with ordinary employees accounting for the most (32.5\%). Most of the tourists interviewed are Mianyang local residents, accounting for $68.5 \%$. See Figure 2 for the results. 


\subsection{Cluster Analysis of Social Value Space}

The SolVES model is used to analyze the average nearest neighbor of $3493 \mathrm{col}-$ lected social value points, and the statistical table of spatial clustering is generated (Table 2). The spatial clustering of the running results of the model is judged by the $\mathrm{R}$ ratio less than 1 and the larger negative $\mathrm{Z}$ score. The quantity $(\mathrm{N})$ of each type of value mark is used to jointly determine the preference degree of respondents' value. From Table 2, it can be clearly seen that the spatial distribution of all social value types in Mianyang People's Park belongs to the clustering model $(R<1)$, and the $Z$ value is low, and the spatial clustering of the model results is good, among which the historical and cultural value points have the highest clustering degree. When based on all interviewees, people clearly prefer recreational value, aesthetic value, therapeutic value, and historical and cultural value. However, based on subgroups, there are some differences. Some value points are too few and scattered. After secondary mapping, it is impossible to generate a spatial map and complete the calculation of the maximum value index. However, some value points are not even perceived by some subgroups. For example, for the park staff, they all think that the park has no scientific research, education and spiritual value. Therefore, based on these two subgroups, the research mainly focuses on the four types of values of recreation, aesthetics, therapeutic, and history and culture to conduct more in-depth research to explore the impact of demographic differences on the spatial distribution of values.

Table 2. Spatial agglomeration table of 9 social value types of people's park.

\begin{tabular}{|c|c|c|c|c|c|c|c|c|c|c|c|c|}
\hline \multirow{3}{*}{ Social value type } & \multicolumn{6}{|c|}{ Point Counts (N) } & \multicolumn{6}{|c|}{$\mathrm{R}$ ratio (Z score) } \\
\hline & \multirow{2}{*}{$\begin{array}{c}\text { All } \\
\text { surveys }\end{array}$} & \multicolumn{5}{|c|}{ Subgroup Survey } & \multirow{2}{*}{$\begin{array}{c}\text { All } \\
\text { surveys }\end{array}$} & \multicolumn{5}{|c|}{ Subgroup Survey } \\
\hline & & Male & Female & Tourist & Expert & Staff & & Male & Female & Tourist & Expert & Staff \\
\hline Aesthetic & 485 & 232 & 253 & 346 & 99 & 40 & $\begin{array}{c}0.46 \\
(-22.69)\end{array}$ & $\begin{array}{c}0.44 \\
(-16.24)\end{array}$ & $\begin{array}{c}0.48 \\
(-15.78)\end{array}$ & $\begin{array}{c}0.47 \\
(-18.83)\end{array}$ & $\begin{array}{c}0.42 \\
(-10.95)\end{array}$ & $\begin{array}{c}0.60 \\
(-4.84)\end{array}$ \\
\hline Biodiversity & 155 & 62 & 93 & 129 & 23 & 3 & $\begin{array}{c}0.57 \\
(-10.24)\end{array}$ & $\begin{array}{c}0.69 \\
(-4.60)\end{array}$ & $\begin{array}{c}0.60 \\
(-7.32)\end{array}$ & $\begin{array}{c}0.61 \\
(-8.51)\end{array}$ & $\begin{array}{c}0.55 \\
(-4.17)\end{array}$ & $\begin{array}{c}1.35 \\
(1.15)\end{array}$ \\
\hline Economic & 189 & 85 & 104 & 128 & 45 & 16 & $\begin{array}{c}0.36 \\
(-16.71)\end{array}$ & $\begin{array}{c}0.45 \\
(-9.79)\end{array}$ & $\begin{array}{c}0.41 \\
(-11.58)\end{array}$ & $\begin{array}{c}0.37 \\
(-13.54)\end{array}$ & $\begin{array}{c}0.40 \\
(-7.73)\end{array}$ & $\begin{array}{c}0.55 \\
(-3.47)\end{array}$ \\
\hline $\begin{array}{l}\text { Historical and } \\
\text { Cultural }\end{array}$ & 315 & 146 & 169 & 225 & 66 & 24 & $\begin{array}{c}0.33 \\
(-22.82)\end{array}$ & $\begin{array}{c}0.37 \\
(-14.50)\end{array}$ & $\begin{array}{c}0.34 \\
(-16.29)\end{array}$ & $\begin{array}{c}0.34 \\
(-18.85)\end{array}$ & $\begin{array}{c}0.17 \\
(-12.87)\end{array}$ & $\begin{array}{c}0.28 \\
(-6.72)\end{array}$ \\
\hline $\begin{array}{l}\text { Scientific Research } \\
\text { and Educational }\end{array}$ & 128 & 50 & 78 & 108 & 20 & 0 & $\begin{array}{c}0.50 \\
(-10.90)\end{array}$ & $\begin{array}{c}0.51 \\
(-6.60)\end{array}$ & $\begin{array}{c}0.52 \\
(-8.11)\end{array}$ & $\begin{array}{c}0.52 \\
(-9.52)\end{array}$ & $\begin{array}{c}0.51 \\
(-4.22)\end{array}$ & - \\
\hline Life Sustaining & 134 & 51 & 83 & 109 & 21 & 4 & $\begin{array}{c}0.56 \\
(-9.74)\end{array}$ & $\begin{array}{c}0.67 \\
(-4.45)\end{array}$ & $\begin{array}{c}0.61 \\
(-6.72)\end{array}$ & $\begin{array}{c}0.62 \\
(-7.55)\end{array}$ & $\begin{array}{c}0.47 \\
(-4.64)\end{array}$ & $\begin{array}{c}0.73 \\
(-1.04)\end{array}$ \\
\hline Recreation & 1591 & 718 & 873 & 1168 & 213 & 210 & $\begin{array}{c}0.54 \\
(-35.21)\end{array}$ & $\begin{array}{c}0.56 \\
(-22.63)\end{array}$ & $\begin{array}{c}0.53 \\
(-26.62)\end{array}$ & $\begin{array}{c}0.55 \\
(-29.49)\end{array}$ & $\begin{array}{c}0.51 \\
(-13.55)\end{array}$ & $\begin{array}{c}0.47 \\
(-14.60)\end{array}$ \\
\hline Spiritual & 161 & 70 & 91 & 129 & 32 & 0 & $\begin{array}{c}0.50 \\
(-12.13)\end{array}$ & $\begin{array}{c}0.57 \\
(-6.88)\end{array}$ & $\begin{array}{c}0.47 \\
(-9.72)\end{array}$ & $\begin{array}{c}0.49 \\
(-10.99)\end{array}$ & $\begin{array}{c}0.57 \\
(-0.57)\end{array}$ & - \\
\hline Therapeutic & 335 & 153 & 182 & 260 & 61 & 14 & $\begin{array}{c}0.51 \\
(-17.01)\end{array}$ & $\begin{array}{c}0.50 \\
(-11.86)\end{array}$ & $\begin{array}{c}0.51 \\
(-12.71)\end{array}$ & $\begin{array}{c}0.52 \\
(-14.52)\end{array}$ & $\begin{array}{c}0.42 \\
(-8.73)\end{array}$ & $\begin{array}{c}0.83 \\
(-1.21)\end{array}$ \\
\hline
\end{tabular}




\subsection{Stakeholder Groups' Preference for Social Values}

\subsubsection{Spatial Distribution of Social Value Based on Gender Differences}

The social value distribution of the People's Park based on the gender group survey is shown in Figure 3. The distribution areas of historical and cultural value are similar, and the high VI areas represented by red are concentrated in the Monument, Deng Jiaxian Square and Cultural Square. However, aesthetics, recreation, biodiversity, spirituality, therapeutic, and economic values are different. Among these different types of values, the distribution map of aesthetics and therapeutic values shows that males with high VI represent more red areas

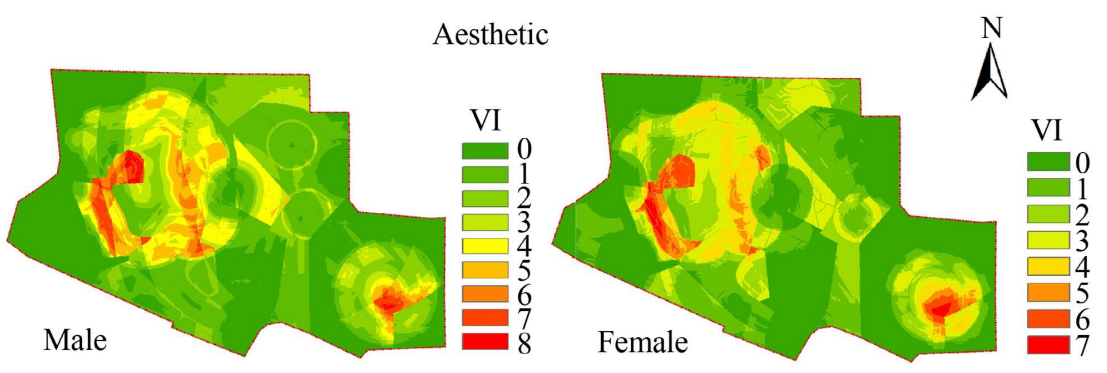

Historical and Cultural

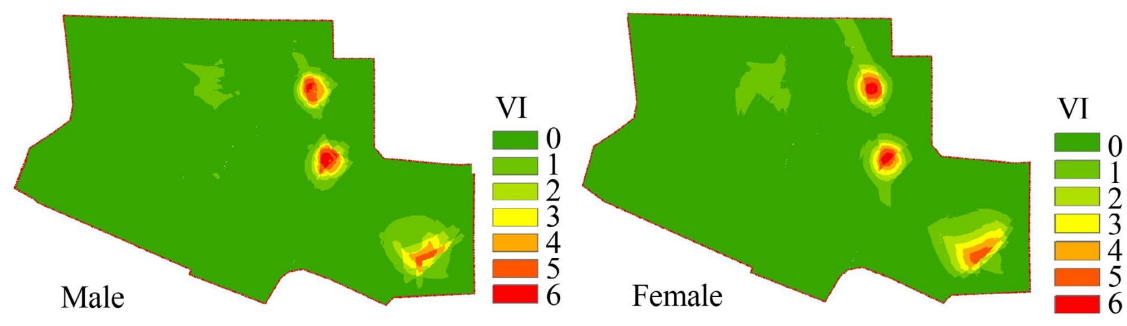

Recreation

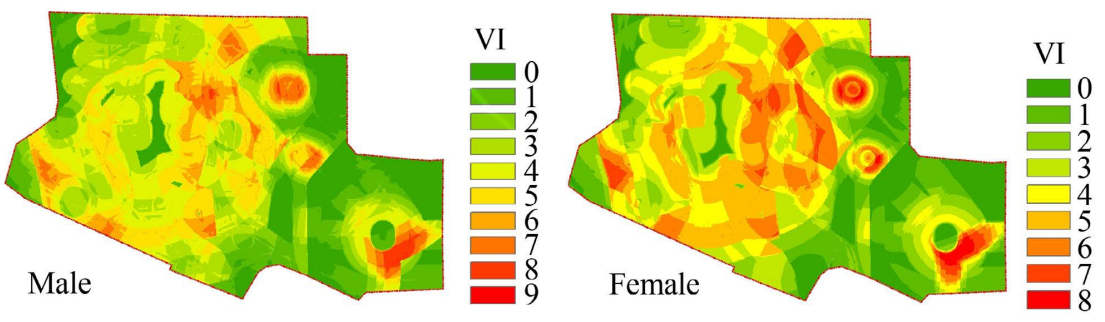

Therapeutic
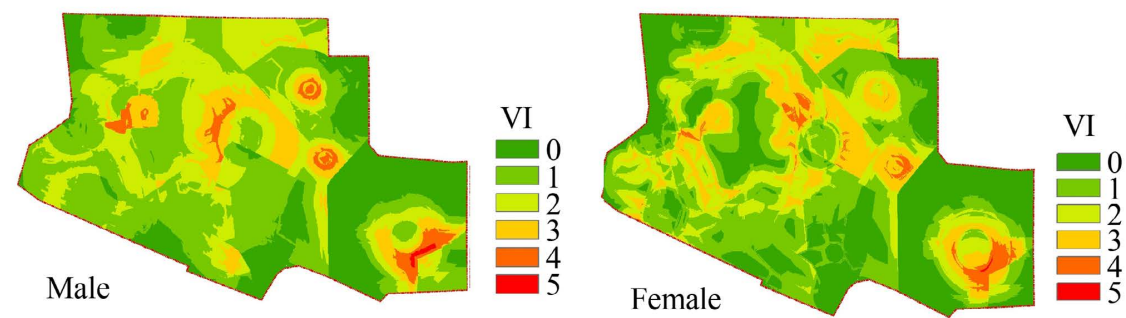

$\begin{array}{llll}\text { Legend } & 0 & 0.05 \quad 0.1 \\ \quad & & \end{array}$

Figure 3. Spatial distribution of social value of people's parks based on gender difference group survey. 
than females, while recreation is just the opposite. The value result shows that the red color of the female group is more obvious, and there are more display areas, which also shows that men are more tolerant in landscape aesthetics than women, and pay more attention to the value brought by some leisure and fitness activities to the public. In contrast, what women are more interested in is the recreation value brought to the public by park places and facilities, and they are more concerned about a sense of pleasure and excitement immediately generated by various entertainment facilities. In addition, combined with the maximum value index table based on the gender group (Table 3), it can be seen that there are differences between men and women in the same type of maximum VI, and the maximum value index of men in aesthetics and recreation is slightly higher than that of women, which indicates that men have obvious targeted areas and concentration of values, such as Peach Blossom Island, Cycad Garden and Cultural Square area, simple landscape and hydrophilic leisure space can better satisfy their aesthetic, recreation and recreation needs. Even men are more aware of the value of biodiversity. However, biodiversity in this study pays more attention to the diversity of plant species, which shows that male tourists pay more attention to the composition of plant communities and the distribution of plant species than female tourists.

\subsubsection{Spatial Distribution of Social Value Based on Identity Differences}

In addition to gender differences, the article also studied the similarities and differences of tourists, experts and park staffs' perceptions of park ecosystem service preferences and social values. The results showed that there were obvious differences among the three groups (Figure 4). Compared with tourists, the aesthetic value of experts and staff is more concentrated, and experts are more aware of the aesthetic value brought by the park landscape. This is because most experts are more professional in landscape collocation, plant growth and other issues, and pay more attention to the value of plant growth and the ecological and aesthetic value brought by the future, while the words of staff and tourists pay more attention to the beauty perceived by the first sight, but the maximum VI of the staff in the park is low, and it is also because they have worked in the park for a long time. However, the distribution of historical and cultural values is similar, and the staff in the park reflect that although there are monuments and memorial squares, for those who have worked here for a long time, the park can't meet the needs of historical and cultural dissemination and learning, and

Table 3. The maximum attained on the value index (Max VI) of the social values based on gender.

\begin{tabular}{ccccccccc}
\hline $\begin{array}{c}\text { Social } \\
\text { value } \\
\text { type }\end{array}$ & Aesthetic & Biodiversity & Economic & $\begin{array}{c}\text { Historical } \\
\text { and } \\
\text { Cultural }\end{array}$ & $\begin{array}{c}\text { Scientific } \\
\text { Research and } \\
\text { Educational }\end{array}$ & $\begin{array}{c}\text { Life } \\
\text { Sustaining }\end{array}$ & Recreation & Spiritual Therapeutic \\
\hline $\begin{array}{c}\text { Male } \\
\text { Female }\end{array}$ & 8 & 1 & - & 6 & 1 & - & 9 & - \\
\hline
\end{tabular}




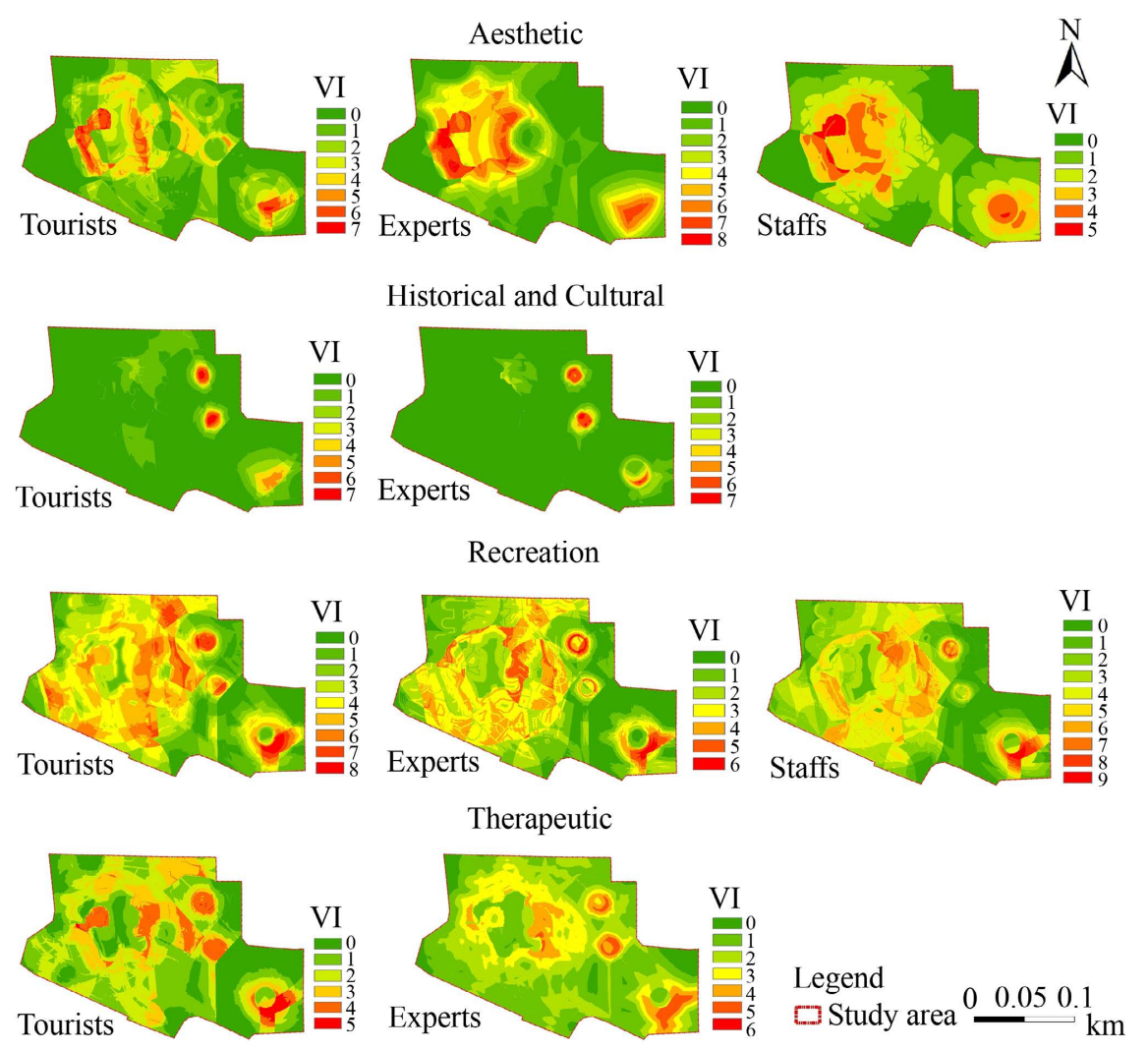

Figure 4. Spatial distribution of social value of people's parks based on identity difference group survey.

can't feel the generation of such values. There are similar problems in the value of health care. The Park doesn't even have some fitness facilities and fitness zones to meet the public's health care needs. Finally, the high VI area of tourists' entertainment value is significantly higher than that of experts and employees.

In addition, as can be seen from Table 4, experts can perceive more values of biodiversity and life sustainability, which means that while meeting the needs of the public, experts can better consider the development of ecological culture, as well as the construction supervision and coordination control of urban health care and livable environment for the aged. From the point of view of park staff and tourists, although they may have some differences on the area of value distribution, on the whole, they think that the value of ecological and cultural services is more direct than that of landscape aesthetics and recreation, and they are more inclined to supply services that can directly generate value benefits and benefits.

\subsection{Model Performance Evaluation}

The reliability of SolVES model is evaluated by AUC statistics. When AUC is greater than 0.7 , it is judged that the model evaluation value is valid, and the larger the AUC value, the higher the reliability of the model evaluation value. According to the area table under the working characteristic curve (Table 5), the 
Table 4. The maximum attained on the value index (Max VI) of the social values based on identity groups.

\begin{tabular}{ccccccccc}
\hline $\begin{array}{c}\text { Social } \\
\text { value } \\
\text { type }\end{array}$ & Aesthetic & Biodiversity & Economic & $\begin{array}{c}\text { Historical } \\
\text { and } \\
\text { Cultural }\end{array}$ & $\begin{array}{c}\text { Scientific } \\
\text { Research and } \\
\text { Educational }\end{array}$ & $\begin{array}{c}\text { Life } \\
\text { Sustaining }\end{array}$ & Recreation & Spiritual Therapeutic \\
\hline Tourists & 7 & - & - & 7 & - & - & 8 & - \\
Experts & 8 & 1 & - & 7 & - & 1 & 6 & - \\
Staffs & 5 & - & 1 & - & - & 1 & 9 & - \\
\hline
\end{tabular}

Table 5. AUC statistics of each social value type in PPMC.

\begin{tabular}{ccc}
\hline Social value type & Training AUC & Test AUC \\
\hline Aesthetic & 0.880 & 0.872 \\
Historical and Cultural & 0.956 & 0.942 \\
Recreation & 0.784 & 0.757 \\
Therapeutic & 0.846 & 0.793 \\
\hline
\end{tabular}

AUC values evaluated by the model are all greater than 0.7 , which shows that the evaluation results of the model are reliable.

\section{Discussion}

The marked number of social value points shows that the park has high aesthetic, recreational, historical, cultural and healthy values. The aesthetic value and recreational value of the park are also recognized by most people, and the value index is high. However, there are some differences between the historical and cultural values and the values of health care. Park staff can hardly perceive the historical and cultural value and the health value of the park, and experts' perception of these two values is lower than that of tourists, which also reflects the shortcomings of park construction. Mianyang People's Park, as one of the patriotic bases in Mianyang City, has historical landmarks such as Deng Jiaxian Square and Liberation Monument. It can make good use of the characteristics of Mianyang Science and Technology City to spread these cultures by means of modern wisdom screen and immersive image education, instead of building historical and cultural landscape by a sculpture or a square. In addition, there are a large number of residential areas around the park, which are important places for a large number of residents to have a rest and entertainment. However, there is a lack of fitness and health facilities in the park, which cannot meet the health needs of urban residents. These two points should be strengthened in the following optimization construction of the park.

The direct driving factor of the social value of ecosystem services is the subjective initiative of human beings, because the results are calculated by investigation. Gender, identity and so on are one of the important factors that affect People's subjective initiative. Our research shows that men prefer aesthetics, 
health and spiritual values, and the high VI of men appears in more areas than that of women. The results of biodiversity and economic value show that the VI areas surveyed and evaluated by women are more than those surveyed and evaluated by men. Moreover, the maximum VI of women is larger than that of men, which has the same conclusion as Gao et al. (2017) who discussed the spatial distribution of social value influenced by gender. In addition to the influence of gender on the value preference of human consumption expenditure, the identity, age, education level and income of the respondents also have an influence on the preference (Semmens, Sherrouse, \& Ancona, 2019). Respondents who are engaged in related majors, are older, well educated, and have higher-than-average family income can better understand the meaning of social value, which may have relatively important significance and reasonable evaluation criteria for social value, and even can be compared and evaluated with other parks.

\section{Conclusion}

In this study, the social value of ecosystem services of Mianyang People's Park was evaluated, the data were collected by questionnaire survey and the value was quantified and mapped by SolVES model. First of all, from the overall data, the People's Park has good aesthetic and recreational values. Although the historical and cultural values and health values are high, they still need to be strengthened in the future optimization design. In addition, the analysis of the article shows that the social value of the park has obvious influence on the gender and identity of the respondents. Finally, the model is well used in the research of social value of comprehensive parks, which proves that People's perception plays an important role in the evaluation of social value, and these data can also be used as useful information for park management and construction. However, this study only focuses on gender and identity, and it is hoped that in the future research, we can take into account broader demographic characteristics such as age and income, integrate planning into all ages, classes and occupations, and integrate public perception and ideas, and strive to realize public participation and public planning.

\section{Conflicts of Interest}

The authors declare no conflicts of interest regarding the publication of this paper.

\section{References}

Bagstad, K. J., Reed, J. M., Semmens, D. J., Sherrouse, B. C., \& Troy, A. (2016). Linking Biophysical Models and Public Preferences for Ecosystem Service Assessments: A Case Study for the Southern Rocky Mountains. Regional Environmental Change, 16, 2005-2018. https://doi.org/10.1007/s10113-015-0756-7

Castro, A. J., Vaughn, C. C., Julian, J. P., \& García-Llorente, M. (2016). Social Demand for Ecosystem Services and Implications for Watershed Management. Journal of the American Water Resources Association, 52, 209-221. 
https://doi.org/10.1111/1752-1688.12379

Cheng, D. Y., Li, M. T., Ding, Y. Y., \& Che, Y. (2018). Assessment of the Urban Waterfront Based on Social Values of Ecosystem Services: A Case Study of the Huangpu River Waterfront. Shanghai Urban Planning Review, 5, 125-130.

Clement, J. M., \& Cheng, A. S. (2011). Using Analyses of Public Value Orientations, Attitudes and Preferences to Inform National Forest Planning in Colorado and Wyoming. Applied Geography, 31, 393-400. https://doi.org/10.1016/j.apgeog.2010.10.001

Coon, J. T., Boddy, K., Stein, K., Whear, R., Barton, J., \& Depledge, M. (2011). Does Participating in Physical Activity in Outdoor Natural Environments Have a Greater Effect on Physical and Mental Wellbeing than Physical Activity Indoors? A Systematic Review. Environmental Science \& Technology, 45, 1761-1772.

Daniels, B., Zaunbrecher, B. S., Paas, B., Ottermanns, R., Ziefle, M., \& Roß-Nickoll, M. (2018). Assessment of Urban Green Space Structures and Their Quality from a Multidimensional Perspective. Science of the Total Environment, 615, 1364-1378. https://doi.org/10.1016/j.scitotenv.2017.09.167

Enriquez-Acevedo, T., Botero, C. M., Cantero-Rodelo, R., Pertuz, A., \& Suarez, A. (2018). Willingness to Pay for Beach Ecosystem Services: The Case Study of Three Colombian Beaches. Ocean and Coastal Management, 161, 96-104.

https://doi.org/10.1016/j.ocecoaman.2018.04.025

Gao, Y., Liu, K., Ma, Q., Li, Y., Fan, Y., Li, X., \& Gu, C. (2017). Assessment of Social Value of Ecosystem Services Based on Solves Model and Visitor's Preference: A Case Study of Taibai Mountain National Forest Park. Chinese Journal of Ecology, 36, 3564-3573.

Graça, M., Alves, P., Gonçalves, J., Nowak, D. J., Hoehn, R., Farinha-Marques, P., \& Cunha, M. (2018). Assessing How Green Space Types Affect Ecosystem Services Delivery in Porto, Portugal. Landscape and Urban Planning, 170, 195-208.

https://doi.org/10.1016/j.landurbplan.2017.10.007

Howley, P., Donoghue, C. O., \& Hynes, S. (2012). Exploring Public Preferences for Traditional Farming Landscapes. Landscape and Urban Planning, 104, 66-74.

https://doi.org/10.1016/j.landurbplan.2011.09.006

Lindemann-Matthies, P., Briegel, R., Schüpbach, B., \& Junge, X. (2010). Aesthetic Preference for a Swiss Alpine Landscape: The Impact of Different Agricultural Land-Use with Different Biodiversity. Landscape and Urban Planning, 98, 99-109.

https://doi.org/10.1016/j.landurbplan.2010.07.015

Madureira, H., Nunes, F., Oliveira, J. V, Cormier, L., \& Madureira, T. (2015). Urban Residents' Beliefs Concerning Green Space Benefits in Four Cities in France and Portugal. Urban Forestry \& Urban Greening, 14, 56-64. https://doi.org/10.1016/j.ufug.2014.11.008

McNally, C. G., Gold, A. J., Pollnac, R. B., \& Kiwango, H. R. (2016). Stakeholder Perceptions of Ecosystem Services of the Wami River and Estuary. Ecology and Society, 21, Article No. 34.

Molnarova, K., Sklenicka, P., Stiborek, J., Svobodova, K., Salek, M., \& Brabec, E. (2012). Visual Preferences for Wind Turbines: Location, Numbers and Respondent Characteristics. Applied Energy, 92, 269-278. https://doi.org/10.1016/j.apenergy.2011.11.001

Ni, T., \& Zuo, Y. (2005). The Key and Difficult Points in Ecocity Planning. Planners, 21, 4.

Nohl, W. (2001). Sustainable Landscape Use and Aesthetic Perception-Preliminary Reflections on Future Landscape Aesthetics. Landscape and Urban Planning, 54, 223-237. https://doi.org/10.1016/S0169-2046(01)00138-4 
Peng, W., Liu, W., Cai, W., Wang, X., Huang, Z., \& Wu, C. (2019). Evaluation of Ecosystem Cultural Services of Urban Protected Areas Based on Public Participation GIS (PPGIS): A Case Study of Gongqing Forest Park in Shanghai, China. Chinese Journal of Applied Ecology, 30, 439-448.

Semmens, D. J., Sherrouse, B. C., \& Ancona, Z. H. (2019). Using Social-Context Matching to Improve Spatial Function-Transfer Performance for Cultural Ecosystem Service Models. Ecosystem Services, 38, Article ID: 100945.

https://doi.org/10.1016/j.ecoser.2019.100945

Shan, X. Z. (2014). Socio-Demographic Variation in Motives for Visiting Urban Green Spaces in a Large Chinese City. Habitat International, 41, 114-120. https://doi.org/10.1016/j.habitatint.2013.07.012

Sherrouse, B. C., Clement, J. M., \& Semmens, D. J. (2011). A GIS Application for Assessing, Mapping, and Quantifying the Social Values of Ecosystem Services. Applied Geography, 31, 748-760. https://doi.org/10.1016/j.apgeog.2010.08.002

Sherrouse, B. C., Semmens, D. J., \& Clement, J. M. (2014). An Application of Social Values for Ecosystem Services (SolVES) to Three National Forests in Colorado and Wyoming. Ecological Indicators, 36, 68-79. https://doi.org/10.1016/j.ecolind.2013.07.008

Shuai, Q., \& Ping, Y. (2014). Cultivation of Ecological Civilization Consciousness Based on Gender Differences. Jiangxi Social Sciences, 34, 206-211.

Spyra, M., Inostroza, L., Hamerla, A., \& Bondaruk, J. (2019). Ecosystem Services Deficits in Cross-Boundary Landscapes: Spatial Mismatches between Green and Grey Systems. Urban Ecosystems, 22, 37-47. https://doi.org/10.1007/s11252-018-0740-3

Strumse, E. (1996). Demographic Differences in the Visual Preferences for Agrarian Landscapes in Western Norway. Journal of Environmental Psychology, 16, 17-31. https://doi.org/10.1006/jevp.1996.0002

Sun, F., Xiang, J., Tao, Y., Tong, C., \& Che, Y. (2019). Mapping the Social Values for Ecosystem Services in Urban Green Spaces: Integrating a Visitor-Employed Photography Method into SolVES. Urban Forestry and Urban Greening, 38, 105-113. https://doi.org/10.1016/j.ufug.2018.11.012

Tufféry, L., Davi, H., López-García, N., Rigolot, E., Jean, F., Stenger, A., \& Lefevre, F. (2021). Adaptive Measures for Mountain Mediterranean Forest Ecosystem Services under Climate and Land Cover Change in the Mont-Ventoux Regional Nature Park, France. Regional Environmental Change, 21, Article No. 12. https://doi.org/10.1007/s10113-020-01732-4

Ulrich, R. S. (1984). View through a Window May Influence Recovery from Surgery. Science, 224, 420-421. https://doi.org/10.1126/science.6143402

van den Bosch, M., \& Sang, A. O. (2017). Urban Natural Environments as Nature-Based Solutions for Improved Public Health-A Systematic Review of Reviews. Environmental Research, 158, 373-384. https://doi.org/10.1016/j.envres.2017.05.040

Vouligny, É., Domon, G., \& Ruiz, J. (2009). An Assessment of Ordinary Landscapes by an Expert and by Its Residents: Landscape Values in Areas of Intensive Agricultural Use. Land Use Policy, 26, 890-900. https://doi.org/10.1016/j.landusepol.2008.10.016

Wang, F., Wang, K., Chen, T., \& Li, P. (2017). Progress and Prospect of Research on Urban Ecological Space. Progress in Geography, 36, 207-218.

Wang, H. (2017). Study on Sponge Construction and Urban Soil and Water Conservation. Architectural Engineering Technology and Design, 5, 2038.

Wang, R., \& Ouyang, Z. (2012). Social-Economic-Natural Complex Ecosystem and Sustainability. Bulletin of Chinese Academy of Sciences, 27, 337-345. 
Wang, Y., Fu, B. T., Lyu, Y. P., Yang, K., \& Che, Y. (2016). Assessment of the Social Values of Ecosystem Services Based on SolVES Model: A Case Study of Wusong Paotaiwan Wetland Forest Park, Shanghai, China. Chinese Journal of Applied Ecology, 27, 1767-1774.

Wu, R. (2000). On The Subject of Urban Green Space System Planning. City Planning Review, 24, 31-33.

Wu, Y., Wang, Z., Su, C., Liu, D., \& Hao, Y. (2018). Discussion on the Concept \& Practice Approach of "Park City." Chinese Landscape Architecture, 34, 4.

Yamashita, S. (2002). Perception and Evaluation of Water in Landscape: Use of Photo-Projective Method to Compare Child and Adult Residents' Perceptions of a Japanese River Environment. Landscape and Urban Planning, 62, 3-17. https://doi.org/10.1016/S0169-2046(02)00093-2

Yang, X., \& Zhang, W. (2016). Combining Natural and Human Elements to Evaluate Regional Human Settlements Quality Based on Raster Data: A Case Study in Beijing-Tianjin-Hebei Region. Acta Geographica Sinica, 71, 2141-2154.

$\mathrm{Yu}, \mathrm{K}$. (1995). Cultural Variations in Landscape Preference: Comparisons among Chinese Sub-Groups and Western Design Experts. Landscape \& Urban Planning, 32, 107-126. https://doi.org/10.1016/0169-2046(94)00188-9

Zeng, F., \& Wu, C. (2019). Spatial Structural Construction Strategy of Park Complex: A Case Study of Singapore. Journal of Chinese Urban Forestry, 17, 40-44.

Zhang, H. (2016). Construction Strategy of Urban Park as a Synthesis in Urban Planning. China Population, Resources and Environment, No. S1, 410-413.

Zhao, J., Zhang, L., \& Wu, H. (2015). Visual Landscape Preference Assessment Overview and Development in the Future. Chinese Landscape Architecture, No. 7, 54-57.

Zhou, L., Guan, D., Huang, X., Yuan, X., \& Zhang, M. (2020). Evaluation of the Cultural Ecosystem Services of Wetland Park. Ecological Indicators, 114, Article ID: 106286. https://doi.org/10.1016/j.ecolind.2020.106286 